\title{
Análise da eficiência das unidades locais da Emater em Goiás: uma abordagem quantitativa
}

\author{
Efficiency analysis of Emater local units in Goiás, Brazil: a \\ quantitative approach

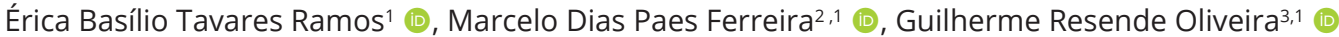 \\ ${ }^{1}$ Programa de Pós-graduação em Agronegócio, Universidade Federal de Goiás (UFG), Goiânia (GO), Brasil. E-mail: \\ ericabasiliotavares@gmail.com \\ ²Departamento de Economia Rural, Programa de Pós-graduação em Economia Aplicada, Universidade Federal de Viçosa (UFV), \\ Viçosa (MG), Brasil. E-mail: marcelo.ferreira@ufv.br \\ 3Instituto Mauro Borges de Estatísticas e Estudos Socioeconômicos (IMB), Goiânia (GO), Brasil. E-mail: resendego@gmail.com
}

Como citar: Ramos, E. B. T., Ferreira, M. D. P., \& Oliveira, G. R. (2022). Análise da eficiência das unidades locais da Emater em Goiás: uma abordagem quantitativa. Revista de Economia e Sociologia Rural, 60(spe), e252837. https://doi. org/10.1590/1806-9479.2021.252837

Resumo: Este trabalho teve por objetivo analisar a eficiência técnica das unidades locais da Emater no estado de Goiás. A abordagem metodológica consiste em um procedimento de dois estágios. O primeiro estágio foi realizado pela Análise Envoltória de Dados (DEA). No segundo estágio, foram utilizadas a regressão Tobit e a Análise de Fronteira Estocástica (SFA) para avaliar as fontes de eficiência. Os resultados do primeiro estágio mostraram que o nível médio da eficiência técnica das unidades locais da Emater em Goiás foi de 0,4013, o que significa que o uso dos insumos poderia ser reduzido em 59,87\%, mantendo-se constante a produção. Foi identificado também que a eficiência de escala média foi de 81,67\%, o que significa dizer que questões relacionadas à escala reduziram a eficiência VRS em 18,33\%, indicando que havia unidades locais atuando com retornos crescentes de escala e com retornos decrescentes de escala. Apenas 15 unidades locais foram eficientes para o modelo com retornos variáveis de escala. No segundo estágio, variáveis como distância da unidade municipal até Goiânia, dependência municipal, rebanho bovino, proporção de funcionários com nível superior e técnico, entre outras, apresentaram significância estatística para explicar a eficiência das unidades locais da Emater em Goiás.

Palavras-chave: extensão rural, políticas públicas, DEA.

\begin{abstract}
This study aimed to analyze the technical efficiency of Emater's local units in the State of Goiás. The methodological approach consists of a two-stage procedure. The first stage was carried out by Data Envelopment Analysis (DEA). In the second stage, Tobit regression and Stochastic Frontier Analysis (SFA) were used to assess the sources of efficiency. The results of the first stage showed that the average level of technical efficiency at Emater's local units in Goiás was 0.4013, which means that the use of inputs could be reduced by $59.87 \%$ keeping production constant. It was also identified that the average scale efficiency was $81.67 \%$, which means that issues related to scaling reduces the VRS efficiency by $18.33 \%$, which indicates that local units are operating with increasing returns to scale and with diminishing returns to scale. Only 15 local units are efficient for the model with variable returns to scale. In the second stage, variables such as the distance from the municipal unit State capital, municipal dependency, cattle herd, proportion of employees with higher education and technical level, among others, were statistically significant to explain the efficiency of the local units of Emater in Goiás.
\end{abstract}

Keywords: rural extension, public policies, DEA.

\section{Introdução}

O setor agropecuário brasileiro enfrenta diversos desafios, entre os quais Vieira Filho (2019) destaca a manutenção eficiente das políticas agrícolas ou a criação de novos instrumentos. Dessa forma, para que esse desafio seja superado, é imperativo reformular o pensamento sobre o meio rural, especialmente para os pequenos agricultores, os quais são muito dependentes da 
reorientação da política agrícola (Buainain et al., 2013). Serviços de assistência técnica e extensão rural (Ater) são importantes nesse contexto, pois contribuem para o processo de inovação produtiva e o desenvolvimento rural por meio do fornecimento de conhecimentos avançados de técnicas agrícolas e de gestão direcionados aos pequenos agricultores (Takahashi et al., 2019). Uma análise mais aprofundada da extensão rural pode contribuir para uma maior percepção da sua importância para o meio rural brasileiro, sendo capaz de favorecer a criação e/ou o aperfeiçoamento de políticas e a melhor alocação de recursos destinados a esse setor (Freitas et al., 2021).

No Brasil, os serviços de Ater tiveram início no final da década de 1940, quando foi criada a Associação de Crédito e Assistência Rural (Acar). Em 1956, a Acar passou a ser coordenada pela Associação Brasileira de Crédito e Assistência Rural (Abcar), após sua expansão no território brasileiro, o que propiciou a institucionalização efetiva do serviço de Ater no país. O apoio federal na extensão rural começou com a criação da Empresa Brasileira de Assistência Técnica e Extensão Rural (Embrater) em 1975. A partir daquele momento, a Abcar foi incorporada pela Embrater, e as Acars (instituições estaduais de Ater) passaram a ser chamadas de Empresas Estaduais de Assistência Técnica e Extensão Rural (Ematers) (Castro \& Pereira, 2017). No início da década de 1980, a oferta de Ater pública reduziu-se significativamente, e somente médios e grandes produtores tinham acesso a assistências privadas (Castro, 2015). Assim, a falta de atuação do poder público passou a ser ainda mais crítica, haja vista a importância da provisão dos serviços de Ater, em que existem falhas de mercado relacionadas à assimetria de informações, externalidades, entre outros (Anderson \& Feder, 2004).

Com a Política Nacional de Assistência Técnica e Extensão Rural (Pnater), lançada em 2004, houve um aumento significativo do apoio federal aos serviços públicos de Ater nos estados, voltados, principalmente, para a agricultura familiar (Peixoto, 2020). No entanto, a grande discussão para a reestruturação da Ater pública no Brasil baseia-se na dificuldade de disponibilidade desses serviços e acesso a eles pela grande maioria dos agricultores familiares. Tais agricultores, além de acesso ao crédito para aquisição de insumos, investimento em benfeitorias e equipamentos e comercialização, dependem também do acesso ao conhecimento sobre como implementar as inovações tecnológicas e como gerir suas atividades (Peixoto, 2014).

Um contexto interessante para entender as políticas de extensão rural no Brasil é o estado de Goiás pela grande relevância econômica do agronegócio. Esse setor tem sustentado o crescimento econômico do estado nos últimos anos (Vicente et al., 2018). Em 2019, o PIB da agropecuária teve um crescimento de $4,1 \%$ em relação a 2018, contra 2,8\% da indústria e 2,2\% dos serviços (Instituto Mauro Borges de Estatísticas e Estudos Socioeconômicos, 2020). Nessa temática, a agricultura familiar também ocupa um papel importante. Em favor disso, a Emater exerce uma função importante, pois dá suporte ao agricultor familiar, principalmente àquele mais carente. Em Goiás, a Emater promoveu a inserção desses agricultores no processo de modernização da agricultura, sendo um canal de acesso entre o conhecimento científico dos órgãos de pesquisa e o meio rural (Miziara, 2007). Contudo, em que pese a proposta de fortalecimento da Ater com o advento do Pnater e o aumento no repasse do governo federal, os gastos com Emater em Goiás caíram aproximadamente $29 \%$ em valores nominais de 2019 para 2020, passando de $R \$ 143,4$ milhões para $R \$ 101,9$ milhões (Goiás, 2019, 2020). Essa redução ocorreu em razão da restrição orçamentária, motivada por uma crise fiscal no estado e no país. Diante disso, um dos desafios da oferta desses serviços públicos são os orçamentos adequados para atender à crescente demanda da agricultura. Nesse cenário, a atuação do Estado tem que ser feita mediante o uso mais racional dos recursos, a fim de obter o máximo atendimento às demandas sociais a partir dos recursos disponíveis. 
Em 2017, a assistência técnica advinda do governo (federal, estadual e municipal) representava $43 \%$ do total no Brasil para a agricultura familiar. Para Goiás, esse cenário foi distinto, haja vista que a assistência técnica do governo equivalia a 26\%. Ademais, o número de estabelecimentos rurais familiares em Goiás aumentou em mais de $8 \%$ entre os dois últimos Censos Agropecuários de 2006 e 2017, passando de 88.326 para 95.684 (Instituto Brasileiro de Geografia e Estatística, 2006, 2017). Em 2017, o número de estabelecimentos rurais familiares em Goiás que receberam assistência técnica do governo (federal, estadual e municipal) era de 3.897; esse número foi reduzido em aproximadamente 67\% comparado aos dados do Censo Agropecuário de 2006, quando os estabelecimentos que receberam assistência do governo eram de 11.675 (Instituto Brasileiro de Geografia e Estatística, 2006, 2017). Uma justificativa para essa redução é que, apesar de a ajuda federal ter aumentado no período tratado, ela continuou escassa e insuficiente para atender os agricultores familiares do estado. Outra justificativa está ligada à ausência de concursos públicos da instituição desde a década de 1990, e soma-se a isso uma maior participação da Ater privada e proveniente de instituições como o Sistema S e ONGs.

Em 2016, os serviços de Ater em Goiás foram mais demandados pelas atividades agropecuárias, correspondendo a $66 \%$ dos atendimentos realizados, e os 34\% restantes estavam distribuídos entre as atividades de aquicultura, extrativismo, pesca, artesanato, silvicultura, turismo rural, entre outros. Dos 66\% da atividade agropecuária, 67\% dos atendimentos foram destinados à pecuária, e 33\%, à agricultura. Em relação à pecuária, as atividades de bovinocultura de leite (73\%) e de corte (26\%) foram as que demandaram mais Ater (Oliveira et al., 2017).

Por meio da análise do perfil do estado de Goiás, é possível perceber a importância da presença das unidades locais da Emater nos municípios. Em 2016, a Emater estava presente em 203 municípios dos 246 municípios goianos, representando 82\%. Essa presença é importante porque garante o acompanhamento do técnico ou extensionista, isto é, possibilita que os serviços de Ater cheguem aos agricultores familiares (Oliveira et al., 2017).

Dentro desse contexto, a escassez de recursos públicos faz com que haja a necessidade de que sejam utilizados da maneira mais eficiente possível, sobretudo no atual cenário de restrições orçamentárias apresentadas anteriormente. Em outras palavras, tal cenário de restrição orçamentária tem que ter o impacto mínimo nos serviços prestados pelas unidades, quais sejam: atendimentos, auxílio na concessão de crédito rural e realização de eventos de extensão. Dentro da literatura, uma das principais abordagens para analisar o desempenho do uso de recursos públicos é a partir de indicadores de eficiência. Uma série de trabalhos aplicou análises de eficiência nas áreas da saúde (Daniel \& Gomes, 2015) da educação (Silva \& Almeida, 2012) e nos serviços públicos municipais (Sousa \& Ramos, 1999).

Dado o exposto, a contribuição deste trabalho está na análise da eficiência técnica dos serviços públicos oferecidos pela Emater de Goiás e em verificar quais fatores são relevantes para determinar a eficiência das unidades locais da entidade estadual. A partir dos resultados, pode-se auxiliar na elaboração de políticas voltadas para a extensão rural ou na reestruturação das políticas já existentes. Entre as informações relevantes para as políticas públicas estão: a identificação de unidades locais de referência (as mais eficientes), a análise da escala de operação para o possível redimensionamento de unidades locais e a relação de variáveis de escolha do gestor público (como nível de educação dos funcionários) no nível de eficiência.

Para obter os resultados, foi utilizada a análise da eficiência em dois estágios. No primeiro estágio, foram calculados os escores de eficiência técnica das unidades locais da Emater de Goiás por meio da Data Envelopment Analysis (DEA). No segundo estágio, os escores de eficiência obtidos no primeiro estágio foram regredidos contra as variáveis que representavam as fontes dessa eficiência por meio da regressão Tobit e da Stochastic Frontier Analysis(SFA). As análises 
do segundo estágio podem ser úteis para auxiliar os gestores na tomada de decisões referentes às unidades locais, uma vez que se sabe quais são os fatores que influenciam a eficiência, o que auxilia no planejamento de políticas e na determinação de diretrizes capazes de aumentar a eficiência no uso de recursos públicos.

Este trabalho foi estruturado da seguinte forma: na seção 2 está presente a revisão de literatura com a exposição de estudos sobre a extensão rural e seus impactos; já na seção 3, são apresentados a metodologia e os dados da pesquisa; a seção 4 expõe os resultados da pesquisa; e, por fim, na seção 5, estão as conclusões obtidas a partir dos resultados encontrados.

\section{Extensão Rural no Brasil}

A Ater é um instrumento importante de geração de renda para a agricultura familiar. A expansão de políticas relacionadas à Ater, associada a análises sistêmicas para seu constante aperfeiçoamento, é um caminho promissor para o desenvolvimento econômico da agricultura familiar no Brasil (Rocha Junior et al., 2019). Christoplos (2010) define a extensão rural como um sistema que busca facilitar o acesso dos agricultores a tecnologias e informações, facilitar a interação dos agricultores com instituições de pesquisa, educação e outras instituições relevantes e ajudá-los a desenvolver suas próprias habilidades e técnicas organizacionais e de gestão.

Desde o surgimento dos serviços de Ater no Brasil no final da década de 1940, tais serviços eram prestados na sua maioria por instituições públicas, porém, com a implementação da Pnater, a extensão rural tem sido executada também por empresas privadas, empresas integradoras, cooperativas e outras entidades (Pettan, 2010). No entanto, Castro \& Pereira (2017) ressaltaram que a situação de restrição financeira e de recursos humanos das instituições estaduais públicas de Ater pouco mudou com a criação da Pnater. Rocha Junior et al. (2019) ainda destacam que, além da entidade estadual de extensão rural (Emater), existem outras entidades que oferecem o serviço de assistência aos produtores familiares, como algumas agências municipais, estaduais e federais e, principalmente, empresas privadas. No entanto, os autores evidenciaram que a maior parcela de assistência técnica oferecida para agricultores familiares no Brasil era oriunda das agências estaduais da Emater e de empresas privadas.

Serviços de extensão rural públicos têm passado por vários desafios ao longo dos anos (Freitas et al., 2021; Peixoto, 2020). Nesse sentido, Diesel et al. (2008) afirmaram que houve uma revisão no papel do Estado em vários países, dadas as dificuldades encontradas, como o reconhecimento das falhas de mercado e da necessidade de políticas públicas. Assim, foram buscadas formas alternativas de financiamento e oferta desses serviços. Castro \& Pereira (2017) indicaram que, apesar de todos os desafios da extensão rural, é considerado importante o debate sobre a necessidade de se repensar o papel dos serviços de Ater públicos, principalmente para os agricultores familiares. Freitas et al. (2021) ressaltaram que maiores investimentos na política pública de extensão rural podem resultar em maior desenvolvimento rural, sobretudo no que tange ao aumento da eficiência no uso dos insumos produtivos por parte dos produtores. No entanto, é possível notar que, apesar de os pequenos produtores serem o foco principal do serviço de extensão rural, os grandes produtores são os mais beneficiados com a extensão, mesmo considerando apenas o serviço público.

Nos países desenvolvidos, Läpple \& Hennessy (2015) apontaram que os serviços de extensão rural são cada vez mais operados pelo setor privado. No entanto, Garforth et al. (2003) e Anderson \& Feder (2004) afirmaram que governo possui um papel importante na provisão desse serviço, pois age onde existem falhas de mercado, por exemplo, o fornecimento dos serviços de extensão rural, geralmente, é disponível apenas para grandes produtores em regiões intensivas 
em agricultura, ao passo que pequenos produtores em regiões menos favoráveis necessitam desse serviço. Peixoto (2020) também ressaltou que o Estado tem um papel importante, tanto como prestador direto dos serviços de Ater quanto como indutor da sua oferta em mercados ou segmentos em que há propensão à sua contratação direta pelo produtor diretamente de provedores privados desses serviços. Dessa forma, Freitas et al. (2021) apontaram que, para que a extensão rural seja bem-sucedida entre os pequenos produtores, é necessária a ação conjunta de outros mecanismos governamentais, como maior acesso à política de crédito rural, podendo facilitar o acesso de tais produtores a novos conhecimentos oriundos da pesquisa e a novas tecnologias produtivas, grande parte delas já utilizadas pelos grandes produtores.

Braga et al. (2019) observaram que apenas o acesso à extensão rural por parte dos produtores mais pobres não seria suficiente para elevar os níveis de bem-estar social dos produtores, visto que o baixo desempenho da política pode estar atrelado às fortes restrições orçamentárias e à carência de outras políticas complementares. É necessária a ação conjunta com outros instrumentos governamentais de forma a promover o desenvolvimento do capital humano e o aumento da oferta de crédito a esse público.

No geral, é observado pelos trabalhos apresentados nesta seção que a extensão rural desempenha um papel fundamental no desenvolvimento rural no Brasil. No entanto, existe ainda um grande desafio para os serviços de Ater, principalmente quando relacionado aos recursos públicos destinados a esse serviço. Tal cenário indica uma necessidade de incremento na eficiência do uso de recursos por parte de entidades públicas que atuam na extensão.

\section{Metodologia}

\subsection{Primeiro estágio: Data Envelopment Analysis (DEA)}

Para atender aos objetivos propostos no trabalho, foi adotada a metodologia de análise da eficiência em dois estágios, sendo utilizada a Análise Envoltória de Dados (Data Envelopment Analysis - $D E A$ ) no primeiro estágio e a análise de regressão no segundo estágio.

A $D E A$, proposta no estudo seminal de Charnes et al. (1978), é uma técnica baseada em programação linear que é usada para determinar a eficiência de um conjunto de Unidades Tomadoras de Decisão (Decision Making Units - DMUs). A eficiência é uma função da quantidade de insumos (correspondendo aos insumos usados pelas $D M U s$ ) e da quantidade de produtos (ou seja, os resultados das atividades das DMUs) (Falagario et al., 2012). Neste estudo, as DMUs são as unidades locais da Emater de Goiás. Para o cálculo da eficiência, foi utilizada a orientação insumo. A decisão da orientação está relacionada a que perspectiva de desempenho se pretende avaliar as $D M U s$, já que essa orientação indica o potencial de economia de recursos.

Aplicando a dualidade em programação linear, é possível derivar uma forma envoltória do problema originalmente proposto nos trabalhos seminais (Banker et al., 1984; Byrnes et al., 1984; Charnes et al., 1978). Com isso, a eficiência com orientação insumo da i-ésima DMU, considerando-se a pressuposição de retornos constantes de escala, é dada por (Equaação 1):

$$
\begin{aligned}
& \operatorname{MIN}_{\theta, \lambda} \quad \theta, \\
& \text { Sujeito } a: \\
& -y_{i}+Y \lambda \geq 0, \\
& \theta x_{i}-X \lambda \geq 0, \\
& \lambda \geq 0 .
\end{aligned}
$$

em que: $x_{i}$ é o vetor de insumos (custos operacionais e salários mais encargos); $y_{i}$ é o vetor de produtos (atendimentos, crédito rural e eventos); $\theta$ é uma escalar, cujo valor é a medida 
de eficiência da i-ésima $D M U ; Y$ é a matriz que representa a produção de todas as DMUs analisadas e $X$ é a matriz que representa os insumos utilizados por todas as DMUs. Caso o valor de $\theta$ seja igual a 1, a DMU será eficiente; caso contrário, será ineficiente e menor que 1, indicando o potencial de redução no uso de todos os insumos; $\lambda$ é um vetor cujos valores são calculados de forma a obter a solução ótima. Para uma $D M U$ ineficiente, os valores de $\lambda$ serão os pesos utilizados na combinação linear de outras DMUs eficientes, que influenciam a projeção da $D M U$ ineficiente sobre a fronteira calculada. Isso significa que, para uma unidade ineficiente, existe pelo menos uma unidade eficiente, cujos pesos calculados fornecerão a $D M U$ virtual da unidade ineficiente, mediante combinação linear.

Charnes et al. (1978) propuseram o modelo fundamentado em retornos constantes de escala (Constant Returns to Scale - CRS), que consiste em um problema de programação linear que possibilita trabalhar com múltiplos insumos e produtos, mostrando como as DMUs procuram maximizar a quantidade de produtos sujeitos a uma combinação viável de insumos utilizados. Como nem todas as DMUs operam com retornos constantes de escala, o modelo CRS pode resultar em medidas de eficiência técnica distorcidas pela escala. Diante dessa limitação do modelo CRS, Byrnes et al. (1984) e Banker et al. (1984) propuseram um modelo de retornos variáveis da escala (Variable Returns to Scale - VRS), que, diferentemente do CRS, substitui a ideia de proporcionalidade entre insumos e produtos pela ideia de convexidade.

O problema de programação linear com retornos constantes pode ser modificado para atender à pressuposição de retornos variáveis, adicionando-se a restrição de convexidade $\sum \lambda=1$ (Coelli et al., 2005) Equação 2:

$\operatorname{MIN}_{\theta, \lambda} \quad \theta$,

Sujeitoa:

$-y_{i}+Y \lambda \geq 0$,

$\theta x_{i}-X \lambda \geq 0$,

$\sum \lambda=1$

$\lambda \geq 0$.

É possível indicar também se a DMU está operando sob retornos constantes, crescentes e decrescentes de escala. Retornos de escala referem-se ao modo como, sob operação eficiente, a escala afetaria o nível de eficiência. Retornos constantes de escala ocorrem se todos os insumos crescem em dada proporção e a produção cresce na mesma proporção. Retornos crescentes de escala ocorrem se a produção variar de uma maneira mais que proporcional à variação no uso dos insumos. Por fim, retornos decrescentes de escala ocorrem quando todos os insumos crescem na mesma proporção e a produção cresce em uma proporção menor (Debertin, 2012). Essa medida é definida tanto em uma orientação insumo quanto em uma orientação produto como a razão entre eficiência técnica $C R S$ e eficiência técnica pura VRS, expressa na Equação 3:

Eficiência de Escala $=\frac{\text { Eficiência } C R S}{\text { EficiênciaVRS }}$

A eficiência técnica $C R S$ de uma $D M U$ nunca pode exceder sua eficiência técnica pura VRS em qualquer orientação; portanto, a partir da definição de eficiência de escala descrita na Equação 3, conclui-se que sempre a eficiência de escala é menor ou igual a 1 (Fried et al., 2008).

\subsection{Segundo Estágio: Determinantes da Eficiência}

Foram aplicados os modelos de regressão para determinar quais fatores influenciam a eficiência das unidades locais da Emater de Goiás, sendo importante para identificar os fatores 
gerenciais e ambientais de atuação que afetam a eficiência. Tal abordagem é corriqueira na análise da eficiência (Ferreira \& Vieira Filho, 2020; Guerrini et al., 2013; Reinhard et al., 2002), sendo relevante também para captar a aleatoriedade associada a variáveis latentes não observadas pelo analista que não são contabilizadas no primeiro estágio pelo uso da $D E A$. Foram selecionados dois métodos: Tobit e SFA.

Em razão de a variável dependente ser limitada, em que os valores logaritmizados se localizam no intervalo entre 0 e - $\infty$, os modelos clássicos de regressão, como o Mínimos Quadrados Ordinários (Ordinary Least Squares - OLS), podem não ser consistentes, pois contrariam alguns pressupostos do modelo de não viés, eficiência e consistência das estimativas (Ray, 1991). Dessa forma, a regressão Tobittem sido bastante utilizada no segundo estágio da análise de eficiência.

A regressão Tobit é utilizada quando se tem uma amostra censurada, isto é, quando as informações da variável dependente são limitadas em certos valores (Greene, 2012). Com isso, o modelo Tobit é o mais apropriado para este trabalho. Os coeficientes do modelo Tobit não fornecem os efeitos marginais. Para isso, serão estimados os efeitos marginais das variáveis explicativas do modelo.

Como o modelo Tobitnão capta a eficiência residual do modelo, foi utilizada a SFA, proposta, inicialmente, por Aigner et al. (1977) e Meeusen \& Van Den Broeck (1977), em que o termo de erro $\varepsilon_{i}$ tradicionalmente considerado em modelos de regressão possui dois componentes, um para contabilizar os efeitos aleatórios $v_{i}$ e outro para contabilizar a ineficiência tecnológica $u_{i}$ (Greene, 2004). Além disso, $u_{i}$ e $v_{i}$ são independentes e identicamente distribuídos (iid) (Belotti et al., 2013).

É importante ressaltar que a ineficiência da SFA assume diferentes distribuições estatísticas, e as mais utilizadas são a Half-Normal, Normal Truncada e Exponencial (Ferreira \& Vieira Filho, 2020; Freitas et al., 2021; Silva et al., 2019). Diante disso, a Equação 4 apresenta o modelo de regressão adotado para os modelos propostos:

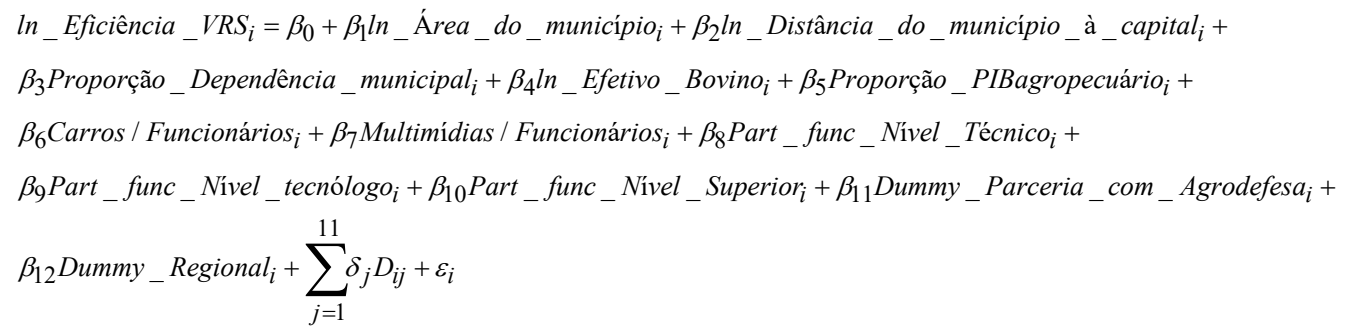

em que: $l n_{-} E f i c i e ̂ n c i a \_V R S_{i}$ é a variável dependente, nesse caso é uma variável limitada, pois as unidades locais que foram eficientes e tiveram escore de eficiência igual a 1 apresentaram valor 0 após a logaritmização; irepresenta as unidades locais da Emater; $\beta_{i}^{\prime}$ s são os parâmetros do modelo; e $\varepsilon_{i}$ é o termo de erro - na SFA esse erro é composto. O modelo possui variáveis categóricas, sendo: Dummy_Parceria_com_Agrodefesa ${ }_{i}$, que caracteriza se a unidade local possui ou não parceria com a Agrodefesa, isto é, se suas unidades se localizam no mesmo espaço físico, em que se assume o valor 1 se possui parceria, e 0, caso contrário; Dummy_Regional representa se a unidade local é uma sede Regional da Emater, em que se assume o valor 1 se é sede regional, e 0, caso contrário; representa os coeficientes das variáveis dummies que indicam as divisões regionais da Emater; $j$ representa a região; $i$ diz respeito às unidades locais da Emater; e $D_{i j}$ se refere à Dummy, que indica se a unidade $i$ está localizada na região j. Apesar de as dummies de região não mostrarem os motivos da heterogeneidade regional, controlam o efeito de tais fenômenos. As demais variáveis são caracterizadas como contínuas: 
In_Area_do_municipio ${ }_{i}$ representa a variável logaritmizada da área em quilômetros quadrados do município; In_Distância_do_município_à_capital ${ }_{i}$ é a variável logaritmizada da distância do município até a capital (Goiânia); Proporção_Dependência_municipal ${ }_{i}$ é a proporção de dependência municipal representada pela participação dos gastos municipais no orçamento das unidades ou cessão de espaço municipal para a instalação da Emater; In_Efetivo_Bovino $i_{i}$ representa a variável logaritmizada do efetivo bovino (quantidade de cabeças); Proporşão_PIBagropecuário $i_{i}$ representa a proporção do PIB da agropecuária em relação ao PIB total do município; Carros / Funcionários ${ }_{i}$ é a proporção de carros nas unidades locais da Emater em relação ao número de funcionários; Multimidias / Funcionários ${ }_{i}$ é a proporção de multimídias em relação ao número de funcionários; Part_func_Nivel_Técnico $o_{i}$ é a proporção de funcionários com ensino técnico; Part_func_Nivel_tecnólogo $o_{i}$ é a proporção de funcionários com ensino tecnólogo; e Part_func_Nivel_Superior $r_{i}$ é a proporção de funcionários com ensino superior.

Quanto aos efeitos dos coeficientes das variáveis explicativas, espera-se que a distância do município até a capital (Goiânia) tenha um coeficiente negativo, isto é, quanto maior a distância do município à capital, menor a eficiência da unidade local da Emater, pois a unidade que está perto da capital tem facilidade no acesso a informações e contato mais direto com a sede da Emater e outros órgãos estatais.

Quanto ao tamanho do município, espera-se um coeficiente negativo, pois, quanto maior a área do município, maior a dificuldade de prestar assistência por causa dos seus custos logísticos; logo, menor a eficiência da unidade. Para a razão entre o PIB da agropecuária e o PIB total, que capta o efeito da renda do município em relação à agropecuária, espera-se um coeficiente positivo, pois, quanto maior a parcela do PIB agropecuário municipal sobre o PIB total municipal, maior a eficiência da unidade local.

No caso da razão entre números de veículos e número de funcionários, espera-se um coeficiente positivo, pois, quanto maior o número de transportes, maior a facilidade para o deslocamento dos agentes extensionistas às propriedades demandantes do serviço de extensão rural. Espera-se que a razão entre o número de multimídias e o número de funcionários apresente um coeficiente positivo, já que, quanto maior o número de recursos digitais, como computadores, maior a eficiência dos serviços administrativos e, consequentemente, das unidades locais. Quanto ao efetivo bovino, espera-se um coeficiente negativo. Segundo Oliveira et al. (2017), as atividades de bovinocultura de leite (73\%) e de corte (26\%) são as que demandam maior foco da Ater em Goiás. Logo, o excesso dessa demanda acarreta uma diminuição da eficiência das unidades locais, haja vista que o oferecimento de Ater por parte das unidades é fixo e não varia com a demanda.

Para a Dummy que representa se a unidade local da Emater possui parceria com a Agrodefesa, espera-se uma relação positiva, o que indica uma sinergia entre as instituições, e, consequentemente, a eficiência é maior. Para a Dummy que representa se a unidade local é uma sede regional, espera-se um coeficiente positivo, pois a regional é responsável pela gestão das unidades locais, de modo que possui mais recursos gerenciais e, consequentemente, a eficiência é maior. Quanto às regiões do estado de Goiás, esperam-se efeitos diversos, dadas as diferentes particularidades relacionadas ao tema abordado, e, apesar de não mostrarem os motivos da heterogeneidade regional, controlam o efeito de tais fenômenos. 


\subsection{Fontes de Dados}

No primeiro estágio, as variáveis foram coletadas do levantamento sistemático dos dados administrativos da Emater de Goiás de 2017, disponibilizado diretamente pela instituição (Emater Goiás, 2021). No segundo estágio, foram utilizados também os dados do levantamento sistemático dos dados administrativos da Emater de Goiás de 2017, complementados por dados do Instituto Brasileiro de Geografia e Estatística (IBGE) e do Instituto Mauro Borges de Estatísticas e Estudos Socioeconômicos (IMB), vinculado ao governo estadual. Para estimação dos resultados, foi utilizado o software Stata 16 IC, e, para construção dos mapas, foi utilizado o software QGIS.

Em 2017, a Emater possuía 203 unidades locais em Goiás. No entanto, a amostra do estudo consistiu em 178 unidades locais, consideradas aptas para análises estatísticas, em razão da disponibilidade dos dados. O Quadro 1 apresenta as variáveis selecionadas para o primeiro estágio, as quais dizem respeito às variáveis internas das unidades locais da Emater. A escolha dos insumos e produtos para a $D E A$ foi embasada em quais variáveis representariam o uso dos recursos e os serviços oferecidos pela Emater. Essa escolha pode ser considerada suficiente para analisar a eficiência das unidades, e os resultados podem ser utilizados como parâmetro para tomada de decisão da instituição.

Quadro 1 - Variáveis do primeiro estágio

\begin{tabular}{|c|c|c|}
\hline Variáveis insumos & Unidade de medida & Fonte \\
\hline Custo operacional ${ }^{a}$ & Em reais $(\mathrm{R} \$)$ & Emater (GO) \\
\hline Salários e encargos & Em reais $(R \$)$ & Emater (GO) \\
\hline \multicolumn{3}{|l|}{ Variáveis produtos } \\
\hline Atendimentos & Unidade & Emater (GO) \\
\hline Crédito rural & Em reais $(R \$)$ & Emater (GO) \\
\hline $\begin{array}{c}\text { Eventos (treinamentos, dias de campo, entre } \\
\text { outros) }\end{array}$ & Unidade & Emater (GO) \\
\hline
\end{tabular}

a Variável criada, soma dos custos operacionais e recursos recebidos do município em que a unidade está localizada. Fonte: elaborado pelos autores.

Em razão de muitos valores iguais a 0 nos produtos selecionados para o primeiro estágio, foram somados valores iguais a 1 ao crédito rural e ao número de eventos, para tornar viável o cálculo da DEA. Segundo Pastor (1996), quando existem muitos valores iguais a 0 nos produtos, para tornar válido o cálculo da $D E A$ é necessário apenas que esse produto assuma um valor positivo. Para isso, foi somado 1 nas variáveis produtos, ou seja, um valor insignificante, mas que permite a aplicação do cálculo àquela unidade. Vários trabalhos recentes utilizaram a mesma metodologia para resolver esse problema da presença de valores iguais a 0 nos produtos (Balios et al., 2015; Chang et al., 2017; Simper et al., 2017; Tung et al., 2018).

No segundo estágio, o primeiro passo foi a seleção de prováveis variáveis que poderiam entrar no modelo. Foram selecionadas variáveis geográficas, econômicas, administrativas, entre outras. O Quadro 2 apresenta as variáveis selecionadas para o segundo estágio. 
Quadro 2 - Variáveis do segundo estágio

\begin{tabular}{|c|c|c|c|}
\hline Código & Descrição & $\begin{array}{l}\text { Unidade de } \\
\text { medida }\end{array}$ & Fonte \\
\hline ln_Eficiência__VRS $S_{i}$ & $\begin{array}{l}\text { In Escores de eficiência } \\
\text { das unidades locais }\end{array}$ & Escore & Calculado no trabalho \\
\hline $\ln _{-}$Distância $_{-} \mathrm{do}_{-}$município $_{-} \grave{a}_{-}$capital $_{i}$ & $\begin{array}{l}\text { In Distância do município à } \\
\text { capital (Goiânia) }\end{array}$ & Quilômetros & $\begin{array}{l}\text { Instituto Mauro Borges } \\
\text { de Estatísticas e Estudos } \\
\text { Socioeconômicos (2018) }\end{array}$ \\
\hline $\ln _{-}$Área_do_municipio ${ }_{i}$ & $\begin{array}{l}\text { In Tamanho do município } \\
\text { (em área) }\end{array}$ & $\begin{array}{l}\text { Quilômetros } \\
\text { quadrados }\left(\mathrm{km}^{2}\right)\end{array}$ & $\begin{array}{l}\text { Instituto Mauro Borges } \\
\text { de Estatísticas e Estudos } \\
\text { Socioeconômicos (2018) }\end{array}$ \\
\hline Proporção_PIBagropecuário $_{i}$ & $\begin{array}{l}\text { Proporção PIB da } \\
\text { agropecuária sobre o PIB } \\
\text { total do município }\end{array}$ & Proporção & $\begin{array}{l}\text { Instituto Mauro Borges } \\
\text { de Estatísticas e Estudos } \\
\text { Socioeconômicos (2018) }\end{array}$ \\
\hline Part_func_Nivel_Superior $_{i}$ & $\begin{array}{l}\text { Proporção de funcionários } \\
\text { com ensino superior }\end{array}$ & Proporção & Emater (GO) \\
\hline Part_func_Nível_tecnólogo $o_{i}$ & $\begin{array}{l}\text { Proporção de funcionários } \\
\text { tecnólogos }\end{array}$ & Proporção & Emater (GO) \\
\hline Part_func_Nivel_ Técnico $_{i}$ & $\begin{array}{l}\text { Proporção de funcionários } \\
\text { com ensino técnico }\end{array}$ & Proporção & Emater (GO) \\
\hline Proporção_Dependência_municipal $_{i}$ & $\begin{array}{l}\text { Proporção de dependência } \\
\text { municipal }{ }^{\mathrm{b}}\end{array}$ & Proporção & Emater (GO) \\
\hline Carros / Funcionários ${ }_{i}$ & $\begin{array}{l}\text { Proporção de carros por } \\
\text { número de funcionários }^{c}\end{array}$ & Proporção & Emater (GO) \\
\hline Multimídias / Funcionários $_{i}$ & $\begin{array}{l}\text { Proporção de multimídias } \\
\text { por número de } \\
\text { funcionários }^{\mathrm{d}}\end{array}$ & Proporção & Emater (GO) \\
\hline $\ln _{-}$Efetivo $_{-}$Bovino $_{i}$ & In Efetivo bovino (cabeças) & $\begin{array}{l}\text { Quantidade de } \\
\text { cabeças de gado }\end{array}$ & $\begin{array}{c}\text { Instituto Brasileiro de } \\
\text { Geografia e Estatística } \\
\text { (2018) }\end{array}$ \\
\hline Dummy_Parceria_com_Agrodefes $_{i}$ & $\begin{array}{l}\text { Dummy da parceria da } \\
\text { unidade municipal da } \\
\text { Emater com a Agrodefesa } \\
\text { (0 não possui parceria e } 1 \\
\text { possui parceria) }\end{array}$ & Variável binária & Emater (GO) \\
\hline Dummy_Regional $_{i}$ & $\begin{array}{l}\text { Dummy regional (0 para } \\
\text { não e } 1 \text { para sim) }\end{array}$ & Variável binária & Emater (GO) \\
\hline$D_{i j}$ & $\begin{array}{l}\text { Dummies regionais da } \\
\text { Emater de Goiás, sendo } \\
12 \text { regionais: Estrada de } \\
\text { Ferro, Caiapó, Planalto, Rio } \\
\text { das Antas, Rio dos Bois, Rio } \\
\text { Paranaíba, Rio Vermelho, } \\
\text { Serra da Mesa, Sudoeste, } \\
\text { Sul, Vale do Paranã e Vale } \\
\text { do São Patrício }\end{array}$ & Variável binária & Emater (GO) \\
\hline
\end{tabular}

aVariável criada, razão entre o PIB da agropecuária municipal e o PIB total municipal. 'Variável criada, razão entre os recursos da Emater advindos das contas municipais e o custo operacional. 'Variável criada, razão entre a quantidade de carros das unidades locais e o número de funcionários para explicar a heterogeneidade de eficiência. dVariável criada, razão entre a quantidade de multimídias das unidades locais e o número de funcionários para explicar a heterogeneidade de eficiência. Fonte: elaborado pelos autores.

\section{Resultados e discussão}

A Tabela 1 apresenta as estatísticas descritivas das variáveis selecionadas no primeiro e segundo estágios. A partir de uma análise geral das estatísticas descritivas, foi observado que a amostra era bastante heterogênea, em que os valores dos desvios-padrão calculados 
demonstravam grande dispersão dos dados em relação à média; os valores de máximo e mínimo possuíam grande amplitude; e os coeficientes de variação (desvio-padrão/média) ressaltavam ainda mais a variabilidade da amostra.

Tabela 1 - Estatísticas descritivas das variáveis do primeiro estágio e segundo estágio

\begin{tabular}{|c|c|c|c|c|c|}
\hline & Média & $\begin{array}{l}\text { Desvio- } \\
\text { padrão }\end{array}$ & $\begin{array}{c}\text { Coef. } \\
\text { variação }\end{array}$ & Mínimo & Máximo \\
\hline \multicolumn{6}{|l|}{ Variáveis primeiro estágio } \\
\hline Custo operacional (input) & $25.627,92$ & $14.468,46$ & 0,56 & 302,00 & $104.932,00$ \\
\hline Salários e encargos (input) & 176645,68 & 142768,38 & 0,81 & 9160,00 & $701.933,00$ \\
\hline Atendimentos (output) & 538,99 & 709,02 & 1,32 & 13,00 & $7.263,00$ \\
\hline Crédito rural (output) & $1.042 .779,95$ & $1.909 .050,29$ & 1,83 & 0,00 & $11.238 .968,21$ \\
\hline Eventos (output) & 6,88 & 11,76 & 1,71 & 0,00 & 66,00 \\
\hline \multicolumn{6}{|l|}{ Variáveis segundo estágio } \\
\hline Distância do município à capital & 224,96 & 147,82 & 0,66 & 0,00 & 669,00 \\
\hline Proporção de apoio municipal & 0,63 & 0,20 & 0,32 & 0,00 & 0,91 \\
\hline Área do município $\left(\mathrm{km}^{2}\right)$ & $1.360 .103,05$ & $1.825 .564,99$ & 1,34 & 61,45 & $9.843 .247,00$ \\
\hline Proporção PIB da agropecuária & 0,07 & 0,06 & 0,84 & 0,00 & 0,58 \\
\hline Efetivo bovino (cabeças) & $95.009,92$ & $93.404,21$ & 0,98 & 159,00 & $588.587,00$ \\
\hline Carros/funcionários & 0,58 & 0,39 & 0,67 & 0,00 & 3,00 \\
\hline Multimídias/funcionários & 1,56 & 1,35 & 0,86 & 0,00 & 6,00 \\
\hline Dummy parceria Agrodefesa & 0,33 & 0,47 & 1,44 & 0,00 & 1,00 \\
\hline Regional & 0,07 & 0,25 & 3,73 & 0,00 & 1,00 \\
\hline Part. func. nível superior & 0,37 & 0,36 & 0,97 & 0,00 & 1,00 \\
\hline Part. func. nível tecnólogo & 0,01 & 0,06 & 6,36 & 0,00 & 0,50 \\
\hline Part. func. nível técnico & 0,35 & 0,36 & 1,03 & 0,00 & 1,00 \\
\hline
\end{tabular}

Fonte: elaborada pelos autores a partir dos resultados da pesquisa.

Miziara (2007) destaca a importância da Emater para a produção familiar de Goiás e ressalta que é preciso repensar o serviço de Ater para o pequeno produtor no estado. Ainda nessa temática, segundo Oliveira et al. (2017), 85,7\% do valor adicionado bruto da agropecuária em 2014 foi gerado em municípios que possuíam unidades da Emater. Em 2016, do total, 89\% das Declarações de Aptidão (DAPs) elaboradas estavam nesses municípios, que emitiram, em média, 47,6 DAPs, enquanto os que não tinham Emater produziram 21,3 DAPs.

A Tabela 2 apresenta as estatísticas descritivas das medidas de eficiência calculadas a partir dos insumos e produtos selecionados no trabalho. Com os resultados apresentados na Tabela 2, foi possível identificar que as unidades locais da Emater em Goiás apresentaram alta heterogeneidade na eficiência calculada referente aos recursos aplicados e aos serviços prestados. Segundo Oliveira et al. (2017), existia uma grande heterogeneidade espacial na prestação de serviços da Emater em Goiás, em que algumas unidades regionais chegavam a elaborar dez vezes mais projetos do que outras.

Tabela 2 - Estatísticas descritivas das medidas de eficiência

\begin{tabular}{lccccc} 
& Média & $\begin{array}{c}\text { Desvio- } \\
\text { padrão }\end{array}$ & $\begin{array}{c}\text { Coef. } \\
\text { variação }\end{array}$ & Mínimo & Máximo \\
Eficiência (CRS) & 0,3370 & 0,2623 & 0,7783 & 0,0254 & 1 \\
Eficiência (VRS) & 0,4013 & 0,2757 & 0,6871 & 0,0707 & 1 \\
Eficiência de escala & 0,8167 & 0,2098 & 0,2569 & 0,1625 & 1 \\
\hline
\end{tabular}

CRS: Retornos Constantes de Escala; VRS: Retornos Variáveis de Escala.

Fonte: elaborada pelos autores a partir dos resultados da pesquisa. 
A partir do resultado do modelo CRS, foi observado que, em média, o uso dos insumos poderia ser reduzido em $66,30 \%$, mantendo-se o mesmo nível de produção, caso todas as unidades locais fossem eficientes e atuassem na escala ótima. O que aconteceu também com o modelo $V R S$, visto que o uso dos insumos por unidade local, em média, poderia ser reduzido em $59,87 \%$, mantendo-se constante a produção, caso todas as unidades locais fossem eficientes. Foi constatado também que a média da eficiência de escala foi 0,8167, o que significa dizer que questões relacionadas à escala reduziram a eficiência $V R S$ em 18,33\%, indicando que havia unidades locais atuando com retornos crescentes de escala e com retornos decrescentes de escala. Em outras palavras, em média, a eficiência CRS poderia ser $22,44 \%$ $\left.\left\{[(1-0,8167) / 0,8167]^{*} 100\right)\right\}$ maior se as unidades locais atuassem na escala adequada.

No geral, foi verificado pela média que os escores de eficiência técnica foram baixos, tanto para o modelo CRS quanto para o modelo VRS. Os valores dos desvios-padrão calculados para as eficiências dos modelos $C R S$ e $V R S$ foram 0,26 e 0,27, respectivamente, mostrando grande dispersão das observações em relação à média, refletindo em uma amostra bastante heterogênea do ponto de vista da eficiência. Os valores dos coeficientes de variação reforçam a heterogeneidade das eficiências calculadas. Em relação aos valores mínimos, foi observado que a eficiência do modelo CRS apresentou um valor abaixo do modelo $V R S$, indicando o papel da escala de produção, e os dois modelos apresentaram unidades locais eficientes, que atingiram escores máximos iguais a 1 .

Esse desempenho médio baixo encontrado, além de outros fatores, pode estar atrelado, segundo Braga et al. (2019), às fortes restrições orçamentárias para os serviços de Ater e à carência de outras políticas complementares. Dadas essas restrições de recursos, é necessário, portanto, que se eleve a eficiência das unidades que levam a extensão rural aos agricultores familiares, haja vista que Freitas et al. (2021) indicaram que a eficiência técnica da agricultura é influenciada positivamente pela extensão rural. Além disso, apontaram que havia um potencial grande de aumento da abrangência da extensão rural, dada a baixa eficiência relativa, o que poderia elevar os ganhos produtivos da agropecuária no estado de Goiás.

A Figura 1a apresenta o mapa do estado de Goiás com a distribuição espacial das unidades locais da Emater classificadas de acordo com os escores de eficiência VRS. A cor mais escura exposta no mapa apresenta as unidades locais que obtiveram escores de eficiência mais elevados. Uma das informações relevantes extraídas da Figura 1a é que, em geral, as unidades locais com escores de eficiência mais elevados, geralmente, estavam mais distantes de Goiânia, o que contraria o esperado. Foi percebido também que o intervalo que concentra mais unidades locais foi de 0 a 0,38, sendo 110 unidades locais que apresentaram os escores mais baixos. A cor branca representa os municípios que não tinham unidades da Emater ou que os dados das unidades não estavam disponíveis, portanto, foram excluídos do trabalho. As 15 unidades locais eficientes foram: Água Fria de Goiás, Águas Lindas de Goiás, Baliza, Crixás, Formosa, Formoso, Iporá, Luziânia, Mineiros, Nova Aurora, Ouro Verde de Goiás, Panamá, Porangatu, Quirinópolis e Santa Rosa de Goiás. Dessas 15 unidades, 3 eram sedes regionais, sendo Formosa, Iporá e Mineiros. As 163 unidades restantes não apresentaram escore de eficiência máximo, indicando que, em comparação com as eficientes, poderiam reduzir o uso de insumos sem diminuir os serviços prestados.

A partir do que é observado na Figura 1a, foi possível constatar que não havia um padrão espacial para as unidades locais da Emater eficientes. No entanto, Rocha Junior et al. (2019) destacaram que o fator espacial diz muito sobre o desempenho dos serviços de assistência e extensão rural, principalmente no que tange ao nível de capital social existente em cada região e pela tradição no serviço de Ater. 
Conforme observado na Figura 1b, da amostra total de 178 unidades, 108 obtiveram retornos crescentes, indicando que um aumento no uso de todos os insumos geraria um crescimento no produto mais que proporcional. Na grande maioria, unidades com retornos crescentes de escala eram relativamente pequenas em relação ao uso de insumos; ademais, essas unidades estavam em uma região favorável da fronteira de produção. Do total, 11 unidades locais possuíam retornos constantes, situação em que o crescimento dos produtos era proporcional ao crescimento dos insumos, isto é, o crescimento dos produtos gerados das unidades locais era proporcional ao crescimento dos recursos públicos aplicados. Esse resultado implica um sinal de alerta para os gestores, uma vez que aumentos dos insumos podem acarretar um passo para que as unidades locais apresentem retornos decrescentes de escala, ou seja, as unidades locais sairão da situação de retornos constantes para retornos decrescentes. As 59 unidades locais restantes apresentaram retornos decrescentes de escala, ou seja, a resposta no aumento de todos os insumos gerou um aumento menos que proporcional no produto. Dessas 59 unidades locais, 7 eram sedes regionais: Anápolis, Ceres, Goiás, Iporá, Mineiros, Morrinhos e Posse. As unidades locais que se encontravam nessa situação requerem uma atenção maior em relação à alocação dos recursos, pois os retornos dos gastos são menores que o das unidades com retornos constantes e retornos variáveis de escala.

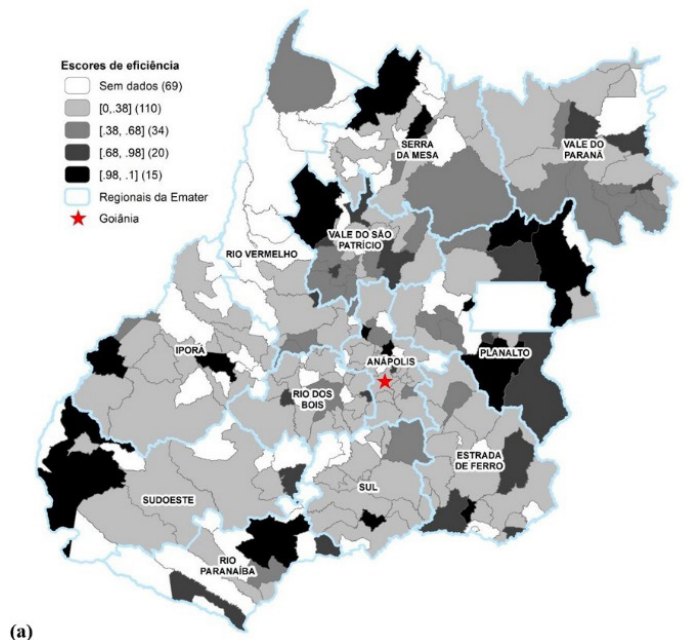

Figura 1 - (a) Distribuição espacial dos escores de eficiência (VRS) das unidades locais da Emater em Goiás e (b) dos retornos de escala das unidades locais da Emater em Goiás. Fonte: elaborada pelos autores a partir dos resultados da pesquisa.

Das 15 unidades locais eficientes do modelo VRS, 11 possuíam retornos constantes, sendo as unidades de Água Fria de Goiás, Águas Lindas de Goiás, Baliza, Formosa, Formoso, Luziânia, Nova Aurora, Ouro Verde de Goiás, Panamá, Porangatu e Santa Rosa de Goiás, enquanto 4 unidades possuíam retornos decrescentes, sendo as unidades de Crixás, Iporá, Mineiros e Quirinópolis. Nenhuma unidade eficiente possuiu retornos crescentes.

Alguns estudos indicam que, para aumentar a abrangência da extensão rural, há a necessidade de aplicação de mais recursos (Oliveira et al., 2017; Peixoto, 2020; Rocha Junior et al., 2020; Freitas et al., 2021); outros indicam que as práticas de gestão devem ser mudadas (Christoplos, 2010; Peixoto, 2014; Rocha Junior et al., 2019). Mendes (2005), no contexto de saúde pública, apontou que o aumento do gasto não significa, necessariamente, o alcance de maior eficiência na gestão dos seus recursos. 
Para o segundo estágio, foram utilizados os modelos Tobit e SFA, este último com três distribuições do termo de erro que representa a ineficiência (Half-Normal, Normal Truncada e Exponencial) para verificar quais variáveis são fontes de eficiência (calculadas no primeiro estágio). A Tabela 3 apresenta o resultado das estimativas para as fontes de eficiência obtido a partir dos modelos propostos. Os resultados dos modelos foram similares entre si.

De início, é importante observar se as variáveis escolhidas para os modelos de fronteira estocástica eram suficientes para explicar a eficiência técnica das unidades locais da Emater de Goiás. Para isso, foram utilizados o teste proposto por Coelli (1995) e os valores críticos de Kodde \& Palm (1986) para 1 grau de liberdade para as distribuições Half-Normale Exponencial e para 2 graus de liberdade para a distribuição Truncada Normal, de acordo com procedimento descrito por Kumbhakar et al. (2015). As estatísticas de teste apresentaram valores menores que os valores críticos de Kodde \& Palm (1986), logo não se rejeita a hipótese nula de não ineficiência técnica, o que indica que não há eficiência residual, sendo a eficiência VRS explicada pelas variáveis utilizadas no segundo estágio e por critérios aleatórios associados ao termo de erro regular.

Tabela 3 - Determinantes da eficiência (VRS) utilizando os modelos Tobit e SFA

\begin{tabular}{|c|c|c|c|c|c|}
\hline In_Eficiência_VRS & $\begin{array}{c}\text { TOBIT } \\
\text { (coeficientes) }\end{array}$ & $\begin{array}{c}\text { TOBIT } \\
\text { (efeitos } \\
\text { marginais) }\end{array}$ & $\begin{array}{l}\text { SFA Half- } \\
\text { Normal }\end{array}$ & $\begin{array}{c}\text { SFA } \\
\text { Truncada- } \\
\text { Normal }\end{array}$ & $\begin{array}{c}\text { SFA } \\
\text { Exponencial }\end{array}$ \\
\hline \multirow[t]{2}{*}{ ln_Área_do_município } & 0,0206 & 0,0190 & 0,0195 & 0,0195 & 0,0195 \\
\hline & {$[0,0253]$} & {$[0,023]$} & {$[0,0234]$} & {$[0,0234]$} & {$[0,0234]$} \\
\hline \multirow[t]{2}{*}{ ln_Distância_município_à_capital } & $0,352^{* \star *}$ & $0,326 * * *$ & $0,306^{* *}$ & 0,306 ** & $0,306^{* *}$ \\
\hline & {$[0,132]$} & {$[0,121]$} & {$[0,122]$} & {$[0,122]$} & {$[0,122]$} \\
\hline \multirow[t]{2}{*}{ Proporção_de_Dependência_Municipal } & $-1,181 * * *$ & $-1,093 * * *$ & $-1,015 * \star *$ & $-1,015^{\star \star \star}$ & $-1,015^{* * *}$ \\
\hline & {$[0,277]$} & {$[0,252]$} & {$[0,247]$} & {$[0,247]$} & {$[0,247]$} \\
\hline \multirow[t]{2}{*}{ In_Efetivo_Bovino } & $-0,0411$ & $-0,038$ & $-0,0441$ & $-0,0441$ & $-0,0441$ \\
\hline & {$[0,0567]$} & {$[0,052]$} & {$[0,0521]$} & {$[0,0521]$} & {$[0,0521]$} \\
\hline \multirow[t]{2}{*}{ Proporção_PIBagropecuário } & 0,899 & 0,831 & 0,815 & 0,815 & 0,815 \\
\hline & {$[0,832]$} & {$[0,768]$} & {$[0,771]$} & {$[0,771]$} & {$[0,771]$} \\
\hline \multirow[t]{2}{*}{ Carros / Funcionários } & $-0,202$ & $-0,187$ & $-0,161$ & $-0,161$ & $-0,161$ \\
\hline & {$[0,182]$} & {$[0,168]$} & {$[0,167]$} & {$[0,167]$} & {$[0,167]$} \\
\hline \multirow[t]{2}{*}{ Multimidias / Funcionários } & $-0,00537$ & $-0,005$ & 0,00435 & 0,00435 & 0,00435 \\
\hline & {$[0,0536]$} & {$[0,049]$} & {$[0,0495]$} & {$[0,0495]$} & {$[0,0495]$} \\
\hline \multirow[t]{2}{*}{ Part_func_Nivel_Técnico } & $1,097 * * *$ & $1,015^{\star * *}$ & $0,978 * * *$ & $0,978 * * \star$ & $0,978 * * *$ \\
\hline & {$[0,277]$} & {$[0,253]$} & {$[0,255]$} & {$[0,255]$} & {$[0,255]$} \\
\hline \multirow[t]{2}{*}{ Part_func_Nivel_Tecnólogo } & 1,058 & 0,979 & 0,917 & 0,917 & 0,917 \\
\hline & {$[0,743]$} & {$[0,686]$} & {$[0,691]$} & {$[0,691]$} & {$[0,691]$} \\
\hline \multirow[t]{2}{*}{ Part._func_Nivel_Superior } & $0,931 * * *$ & $0,862 * \star \star$ & $0,788^{* \star *}$ & $0,788^{* \star \star}$ & $0,788^{* * *}$ \\
\hline & {$[0,261]$} & {$[0,239]$} & {$[0,238]$} & {$[0,238]$} & {$[0,238]$} \\
\hline \multirow[t]{2}{*}{ Dummy_Parceria_com_Agrodefesa } & $-0,0271$ & $-0,025$ & $-0,0139$ & $-0,0139$ & $-0,0139$ \\
\hline & {$[0,112]$} & {$[0,104]$} & {$[0,104]$} & {$[0,104]$} & {$[0,104]$} \\
\hline Dummy_Regional & 0,327 & 0,292 & 0,229 & 0,229 & 0,229 \\
\hline
\end{tabular}

Erros-padrão entre colchetes. * $p<0,10$; ** $p<0,05$; *** $p<0,01$. Fonte: elaborada pelos autores a partir dos resultados da pesquisa. 
Tabela 3 - Continuação...

\begin{tabular}{|c|c|c|c|c|c|}
\hline In_Eficiência_VRS & $\begin{array}{c}\text { TOBIT } \\
\text { (coeficientes) }\end{array}$ & $\begin{array}{c}\text { TOBIT } \\
\text { (efeitos } \\
\text { marginais) }\end{array}$ & $\begin{array}{l}\text { SFA Half- } \\
\text { Normal }\end{array}$ & $\begin{array}{c}\text { SFA } \\
\text { Truncada- } \\
\text { Normal }\end{array}$ & $\begin{array}{c}\text { SFA } \\
\text { Exponencial }\end{array}$ \\
\hline & {$[0,211]$} & {$[0,181]$} & {$[0,190]$} & {$[0,190]$} & {$[0,190]$} \\
\hline \multicolumn{6}{|l|}{ Regiões } \\
\hline \multirow[t]{2}{*}{ Estrada_de_Ferro } & 0,189 & 0,184 & 0,183 & 0,183 & 0,183 \\
\hline & {$[0,236]$} & {$[0,229]$} & {$[0,218]$} & {$[0,218]$} & {$[0,218]$} \\
\hline \multirow[t]{2}{*}{ Planalto } & $0,974 * * *$ & 0,880 & $0,875^{* * *}$ & $0,875^{\star \star *}$ & $0,875^{\text {*** }}$ \\
\hline & {$[0,253]$} & {$[0,224]$} & {$[0,228]$} & {$[0,228]$} & {$[0,228]$} \\
\hline \multirow[t]{2}{*}{ Rio_das_Antas } & $0,826 * *$ & 0,761 & $0,759 * *$ & $0,759 * *$ & $0,759 * *$ \\
\hline & {$[0,330]$} & {$[0,290]$} & {$[0,305]$} & {$[0,305]$} & {$[0,305]$} \\
\hline \multirow[t]{2}{*}{ Rio_dos_Bois } & $0,514^{*}$ & 0,488 & $0,493^{*}$ & $0,493^{*}$ & $0,493^{*}$ \\
\hline & {$[0,293]$} & {$[0,274]$} & {$[0,271]$} & {$[0,271]$} & {$[0,271]$} \\
\hline \multirow{2}{*}{ Rio_Paranaíba } & $0,637 *$ & 0,599 & $0,657 * \star$ & $0,657^{\star *}$ & $0,657^{* *}$ \\
\hline & {$[0,325]$} & {$[0,297]$} & {$[0,298]$} & {$[0,298]$} & {$[0,298]$} \\
\hline \multirow[t]{2}{*}{ Rio_Vermelho } & 0,216 & 0,209 & 0,269 & 0,269 & 0,269 \\
\hline & {$[0,280]$} & {$[0,271]$} & {$[0,259]$} & {$[0,259]$} & {$[0,259]$} \\
\hline \multirow[t]{2}{*}{ Serra_da_Mesa } & 0,217 & 0,210 & 0,221 & 0,221 & 0,221 \\
\hline & {$[0,266]$} & {$[0,257]$} & {$[0,243]$} & {$[0,243]$} & {$[0,243]$} \\
\hline \multirow[t]{2}{*}{ Sudoeste } & 0,0401 & 0,039 & 0,0862 & 0,0862 & 0,0863 \\
\hline & {$[0,306]$} & {$[0,298]$} & {$[0,281]$} & {$[0,281]$} & {$[0,281]$} \\
\hline \multirow[t]{2}{*}{ Sul } & 0,341 & 0,328 & 0,329 & 0,329 & 0,329 \\
\hline & {$[0,265]$} & {$[0,254]$} & {$[0,244]$} & {$[0,244]$} & {$[0,244]$} \\
\hline \multirow[t]{2}{*}{ Vale_do_Paranã } & 0,271 & 0,261 & 0,314 & 0,314 & 0,314 \\
\hline & {$[0,264]$} & {$[0,254]$} & {$[0,244]$} & {$[0,244]$} & {$[0,244]$} \\
\hline \multirow[t]{2}{*}{ Vale_do_São_Patrício } & $0,591 * * *$ & 0,558 & $0,593 * \star *$ & $0,593 * * *$ & $0,593^{* * *}$ \\
\hline & {$[0,226]$} & {$[0,213]$} & {$[0,209]$} & {$[0,209]$} & {$[0,209]$} \\
\hline \multirow[t]{2}{*}{ Constante } & $-3,123^{* * *}$ & & $-2,891 * * *$ & $-2,895^{* \star *}$ & $-2,885^{* \star *}$ \\
\hline & {$[0,915]$} & & {$[1,050]$} & {$[0,951]$} & {$[0,958]$} \\
\hline Chi-Quadrado ineficiência & & & $-0,00002011$ & $-0,00001881$ & $-0,00035461$ \\
\hline Chi-Quadrado teste de Wald & 74,82 & & 90,94 & 90,94 & 90,94 \\
\hline Prob > Chi-Quadrado teste de Wald & 0,000 & & 0,000 & 0,000 & 0,000 \\
\hline AIC & 386,857 & & 360,838 & 362,838 & 360,838 \\
\hline $\mathrm{BIC}$ & 466,260 & & 443,418 & 448,594 & 443,418 \\
\hline
\end{tabular}

Erros-padrão entre colchetes. ${ }^{*} p<0,10 ; * \star p<0,05 ; * \star \star p<0,01$. Fonte: elaborada pelos autores a partir dos resultados da pesquisa.

No que tange aos determinantes da eficiência VRS das unidades locais da Emater de Goiás, foi verificado que existia uma relação positiva entre a distância do município à capital e sua eficiência, isto é, quanto mais distante o município estivesse da capital, mais eficientes seriam suas unidades locais. Esse resultado não era esperado, e uma possível explicação para esse resultado é que a eficiência de escala mostrou que boa parte das unidades mais próximas a Goiânia estavam na faixa de deseconomia de escala, o que indica que havia mais acessos a recursos. Ademais, os gastos com funcionários foram elevados, comparados com unidades mais distantes da capital. Com isso, a estimativa do efeito marginal do modelo Tobit mostrou 
que um acréscimo de $1 \%$ na distância do município da respectiva unidade local até a capital Goiânia aumentaria a eficiência em 0,326\%. Já para a análise dos modelos SFA, um aumento de $1 \%$ na distância aumentaria a eficiência em 0,306\%.

Quanto à proporção de dependência municipal sobre a eficiência das unidades locais, foi observada uma relação negativa, indicando que, quanto maior fosse a proporção de dependência municipal, menor seria a eficiência das unidades. Em média, um aumento de 10 pontos percentuais, ou seja, um aumento de 0,1 na proporção de dependência municipal, resultaria em uma queda de $0,1093 \%$ da eficiência, analisando o efeito marginal do modelo Tobit. Para os modelos $S F A$, um aumento de 10 pontos percentuais na proporção de dependência municipal reduziria a eficiência em $0,1015 \%$. Todas as estimativas apresentaram significância estatística a 1\%. Cabe ressaltar que o município possui papel fundamental sobre as unidades locais, porque nem sempre as unidades são instaladas em seus respectivos imóveis; alguns são cedidos pela prefeitura do município por meio de convênio, que, muitas vezes, também é responsável pela remuneração do técnico responsável pela assistência técnica prestada aos produtores rurais. Em muitos casos, as prefeituras custeiam aluguel, água, energia, veículos e salário, no entanto esse gasto municipal é muito inferior aos recursos do governo estadual na unidade local. O coeficiente negativo pode ser justificado pelo viés local na escolha de recursos humanos e de capital por parte das prefeituras.

Já o efetivo bovino, que representa a maioria da demanda por Ater no estado de Goiás, apresentou coeficiente negativo, mostrando que, quanto maior o número de cabeças de gado no município, menor a eficiência das unidades. A partir da análise do efeito marginal do modelo Tobit, foi constatado que um aumento de $1 \%$ no número de cabeças de gado reduziria a eficiência das unidades locais em $0,038 \%$. Para o modelo $S F A$, foi percebido que um acréscimo de $1 \%$ no número de cabeças de gado reduziria a eficiência das unidades locais em 0,0441\%, no entanto não apresentou significância estatística.

A variável que representa a proporção PIB da agropecuária sobre o PIB total do município não apresentou significância estatística. As variáveis carros/funcionários e multimídias/ funcionários também não apresentaram significância estatística para explicar a eficiência das unidades locais. Quanto à escolaridade, foi notado que os funcionários com nível superior e técnico possuíam significância estatística para explicar a eficiência das unidades, mostrando que, quanto maior a participação de servidores com essa qualificação, mais eficientes as unidades locais. Um resultado interessante é que os coeficientes dessas duas variáveis foram muito próximos, o que indica que um funcionário com nível técnico, nas condições atuais, poderia substituir um funcionário com nível superior. Analisando o efeito marginal do modelo Tobit, foi observado que, em média, um aumento de 10 pontos percentuais, ou seja, um aumento de 0,1 na proporção de funcionários com formação técnica, resultaria no aumento da eficiência em $0,1015 \%$. Para o modelo SFA, um aumento de 10 pontos percentuais na proporção de funcionários com formação técnica implicaria um aumento da eficiência em 0,0978\%. O efeito marginal do modelo Tobit da participação do funcionário com formação superior mostrou que um aumento de 10 pontos percentuais na proporção de funcionários resultaria em um aumento da eficiência em $0,0861 \%$. Por sua vez, o modelo SFA mostrou que um aumento de 10 pontos percentuais na proporção do funcionário com formação superior resultaria em um acréscimo de 0,0788\% na eficiência das unidades locais. Dessa forma, Silva \& Almeida (2012) utilizaram também a escolaridade para mostrar seu efeito sobre o desempenho da gestão pública, verificando que gestores municipais com maiores níveis educacionais promoviam o aumento da eficiência no setor público. 
A Dummy que representa se as unidades locais estavam alocadas com a Agrodefesa não apresentaram significância estatística para determinar a eficiência calculada das unidades locais, o que não indicaria economia de escopo entre as duas atividades oferecidas pelo estado de Goiás. A Dummy que representa se a unidade municipal era uma sede regional também não apresentou significância estatística, ou seja, a unidade estar mais diretamente ligada à gestão regional não mudaria seu nível de eficiência.

$\mathrm{Na}$ análise das 12 regionais da Emater no estado, foi observado que as regionais Planalto, Rio das Antas, Rio dos Bois, Rio Paranaíba e Vale do São Patrício apresentaram significância estatística, e o fato de as unidades locais estarem em tais regiões fez com que a eficiência fosse maior em comparação à regional Caiapó (região de referência), visto que todos os coeficientes foram positivos. Segundo Oliveira et al. (2017), existe uma diferença entre as regionais da Emater de Goiás: enquanto algumas eram responsáveis por mais de $90 \%$ dos lançamentos de DAPs emitidas, outras não conseguiram atingir nem $40 \%$ do total das DAPs elaboradas, em comparação às outras instituições que emitiam DAPs no estado.

\section{Conclusões}

A análise das unidades locais da Emater de Goiás enfatiza que as unidades eficientes ofertavam o maior número de serviços com o menor gasto em relação às demais. Tendo como referência as unidades eficientes, é possível obter ganho significativo na prestação de serviços de Ater no estado. Do total das 178 unidades analisadas, apenas 15 foram eficientes, o que justifica o nível médio da eficiência técnica baixo (40,13\%), e isso significa que o uso dos insumos poderia ser reduzido em 59,87\%, mantendo-se constante a produção.

Outro ponto relevante na análise foi a criação ou a reestruturação de políticas públicas voltadas para os serviços de Ater que concentravam as principais limitações da Emater no estado de Goiás, entre as quais estavam as altas despesas das unidades grandes em relação à menor quantidade de serviços prestados, o que poderia ser resultado da ineficiência de muitas unidades locais. Nesse sentido, a Emater poderia traçar estratégias por meio da aplicação ou realocação de recursos. A aplicação de recursos poderia ser feita em unidades locais com alto nível de eficiência com VRS e que se encontravam na área de retornos crescentes. Já caso o interesse fosse pela realocação de recursos, eles deveriam ser retirados de unidades locais com baixo nível de eficiência VRS e que se encontravam na área de retornos decrescentes. Por fim, os recursos das unidades da Emater deveriam ser realocados de unidades mais próximas à capital para unidades mais distantes. Entende-se que unidades mais distantes da capital gastam menos recursos públicos para entregar os mesmos serviços que unidades mais próximas de Goiânia. No geral, as unidades próximas à capital do estado possuíam gastos mais elevados com pessoal do que unidades mais distantes da capital.

Neste contexto, foi verificado que o resultado da eficiência das unidades locais da Emater não estava relacionado somente ao desempenho da gestão, mas também a outros fatores, por exemplo, fatores geográficos. Neste sentido, enfatiza-se que apenas a destinação de maiores recursos para as unidades locais não eleva a eficiência, mas é necessário considerar fatores externos ao controle do gestor. Portanto, é preciso alinhar a disponibilização de recursos com os fatores externos às unidades.

A análise dos determinantes da eficiência indicou que as unidades locais eficientes que possuíam maior número de funcionários com níveis de qualificação mais elevados estavam mais distantes de Goiânia em relação às demais. Foi identificado também que as unidades 
localizadas nas regionais Planalto, Rio das Antas, Rio dos Bois, Rio Paranaíba e Vale do São Patrício foram mais eficientes e estavam concentradas na parte central do estado de Goiás.

Como trabalhos futuros, sugere-se uma abordagem de dados em painel, o que permitiria acompanhar a evolução do desempenho da Emater de Goiás ao longo do tempo com modelos de decomposição da mudança da produtividade, que, além da escala e eficiência, depende também da mudança tecnológica. Ainda, é possível trabalhar com uma abordagem qualitativa para analisar as questões da realidade local de cada unidade da Emater no estado de Goiás.

\section{Referências}

Aigner, D., Lovell, C. A. K., \& Schmidt, P. (1977). Formulation and estimation of stochastic frontier production function models. Journal of Econometrics, 6, 21-37. http://dx.doi. org/10.1016/0304-4076(77)90052-5

Anderson, J. R., \& Feder, G. (2004). Agricultural extension: good intentions and hard realities. The World Bank Research Observer, 19(1), 41-60. http://dx.doi.org/10.1093/wbro/lkh013

Balios, D., Eriotis, N., Fragoudaki, A., \& Giokas, D. (2015). Economic efficiency of Greek retail SMEs in a period of high fluctuations in economic activity: a DEA approach. Applied Economics, 47(33), 3577-3593. http://dx.doi.org/10.1080/00036846.2015.1019033

Banker, R. D., Charnes, A., \& Cooper, W. W. (1984). Some models for estimating technical and scale inefficiencies in Data Envelopment Analysis. Management Science, 3099), 1078-1092.

Belotti, F., Daidone, S., Ilardi, G., \& Atella, V. (2013). Stochastic Frontier Analysis using Stata. The Stata Journal, 13(4), 719-758. http://dx.doi.org/10.2139/ssrn.2145803

Braga, M. J., Vieira Filho, J. E. R., \& Freitas, C. O. (2019). Impactos da extensão rural na renda produtiva. In IPEA (Org.), Diagnóstico e desafios da agricultura brasileira (pp. 137-160). Rio de Janeiro: IPEA.

Buainain, A. M., Alves, E., Silveira, J. M., \& Navarro, Z. (2013). Sete teses sobre o mundo rural brasileiro. Revista de Política Agrícola, 22(2), 1-25.

Byrnes, P., Färe, R., \& Grosskopf, S. (1984). Measuring productive efficiency: an application to Illinois strip mines. Management Science, 30(6), 671-681. http://dx.doi.org/10.1287/ mnsc.30.6.671

Castro, C. N. (2015). Desafios da Agricultura Familiar : o caso da assistência técnica e extensão rural. Boletim Regional, Urbano e Ambiental, 49-59.

Castro, C. N., \& Pereira, C. N. (2017). Agricultura familiar, assistência técnica e extensão rural e a Política Nacional de Ater. Recuperado em 01 de junho de 2021, de https://www.ipea.gov.br/ portal/index.php?option=com_content\&view=article\&id=31419:td-2343-agricultura-familiarassistencia-tecnica-e-extensao-rural-e-a-politica-nacional-de-ater\&catid=397:2017\&directory $=1$

Chang, Y. T., Lee, S., \& Park, H. (2017). Efficiency analysis of major cruise lines. Tourism Management, 58, 78-88. http://dx.doi.org/10.1016/j.tourman.2016.10.012

Charnes, A., Cooper, W. W., \& Rhodes, E. (1978). Measuring the efficiency of Decision Making Units. European Journal of Operational Research, 2, 429-444. http://dx.doi.org/10.1016/03772217(78)90138-8

Christoplos, I. (2010). Mobilizing the potential of rural and agricultural extension. Rome: FAO. 
Coelli, T. (1995). Estimators and hypothesis tests for a stochastic frontier function: a Monte Carlo analysis. Journal of Productivity Analysis, 6(3), 247-268. http://dx.doi.org/10.1007/ BF01076978

Coelli, T. J., Rao, D. S. P., O'Donnel, C. J., \& Battese, G. E. (2005). Review: an introduction to multivariate statistical analysis, 2nd edition. by T. W. Anderson. Biometrics, 41(3), 815. https://doi.org/10.2307/2531310

Daniel, L. P., \& Gomes, A. P. (2015). Eficiência na oferta de serviços públicos de saúde nos municípios do estado de Mato Grosso. Reflexões Econômicas, 1(1), 179-218.

Debertin, D. L. (2012). Agricultural Production Economics (2nd ed.). Editora: Lexington University of Kentucky.

Diesel, V., Froehlich, J. M., Neumann, P. S., \& Silveira, P. R. C. (2008). Privatização dos serviços de extensão rural: uma discussão (des)necessária? Revista de Economia e Sociologia Rural, 46(4), 1155-1188. http://dx.doi.org/10.1590/S0103-20032008000400010

EMATER GOIÁS. (2021). Emater em tempo real. Recuperado em 27 de julho de 2021, de https:// www.emater.go.gov.br/wp/tempo-real/

Falagario, M., Sciancalepore, F., Costantino, N., \& Pietroforte, R. (2012). Using a DEA-cross efficiency approach in public procurement tenders. European Journal of Operational Research, 218(2), 523-529. http://dx.doi.org/10.1016/j.ejor.2011.10.031

Ferreira, M. D. P., \& Vieira Filho, J. E. R. (2020). Eficiência técnica na agropecuária: capacidade de armazenagem e densidade de rodovias. In J. E. R. Vieira Filho \& J. G. Gasques (Orgs.), Uma jornada pelos contrastes do Brasil: 100 anos de censo agropecuário. Brasília: IPEA.

Freitas, C. O., Silva, F. F., Braga, M. J., \& Neves, M. C. R. (2021). Rural extension and technical efficiency in the Brazilian agricultural sector. The International Food and Agribusiness Management Review, 24(2), 215-232. http://dx.doi.org/10.22434/ifamr2020.0094

Fried, H. O., Lovell, C. A. K., \& Schmidt, S. S. (2008). The measurement of productive efficiency and productivity growth. Oxford: Oxford University Press.

Garforth, C., Angell, B., Archer, J., \& Green, K. (2003). Fragmentation or creative diversity? Options in the provision of land management advisory services. Land Use Policy, 20(4), 323-333. http://dx.doi.org/10.1016/S0264-8377(03)00035-8

GOIÁS. Secretaria de Estado da Economia. (2020). Orçamento Geral do Estado 2020. Diário Oficial (Vol. 183). Goiânia-GO. Recuperado em 27 de julho de 2021, de https://www.economia. go.gov.br/component/content/article/250-planejamento/orçamento/7178-orçamentogeral-do-estado-2020.html

GOIÁS. Secretaria de Estado da Economia. (2019). Orçamento Geral do Estado 2019. Diário Oficial (Vol. 182). Goiânia-GO. Recuperado em 27 de julho de 2021, de https://www.economia. go.gov.br/component/content/article/250-planejamento/orçamento/6440-orçamento-emvigência-2.html?ttemid=101

Greene, W. H. (2004). Distinguishing between heterogeneity and inefficiency: Stochastic frontier analysis of the World Health Organization's panel data on national health care systems. Health Economics, 13(10), 959-980. http://dx.doi.org/10.1002/hec.938

Greene, W. W. H. (2012). Econometric analysis (7th ed.). New York: Prentice Hall. https://doi. org/10.1198/jasa.2002.s458 
Guerrini, A., Romano, G., \& Campedelli, B. (2013). Economies of scale, scope, and density in the Italian Water Sector: a two-stage data envelopment analysis approach. Water Resources Management, 27(13), 4559-4578. http://dx.doi.org/10.1007/s11269-013-0426-9

Instituto Brasileiro de Geografia e Estatística - IBGE. (2017). Censo Agropecuário de 2017. Recuperado em 08 de junho de 2020, de https://sidra.ibge.gov.br/pesquisa/censoagropecuario/censo-agropecuario-2017

Instituto Brasileiro de Geografia e Estatística - IBGE. (2018). Pesquisa da Pecuária Municipal. Recuperado em 20 de outubro de 2018, de https://sidra.ibge.gov.br/pesquisa/ppm/tabelas/ brasil/2019

Instituto Brasileiro de Geografia e Estatística - IBGE. (2006). Censo Agropecuário de 2006. Recuperado em 28 de março de 2020, de https://sidra.ibge.gov.br/pesquisa/censoagropecuario/censo-agropecuario-2006/segunda-apuracao

Instituto Mauro Borges de Estatísticas e Estudos Socioeconômicos- IMB. (2018). Estatísticas Municipais - (Séries Históricas). Recuperado em 20 de outubro de 2018, de https://www. imb.go.gov.br/index.php?option=com_content\&view=article\&id=91\&ltemid=219

Instituto Mauro Borges de Estatísticas e Estudos Socioeconômicos- IMB. (2020). Informe Técnico PIB Goiás - 4o trimestre de 2019 (vol. ano X). Goiânia: IMB.

Kodde, D. A., \& Palm, F. C. (1986). Wald criteria for jointly testing equality and inequality restrictions. Journal of the Econometric Society, 54(5), 1243-1248.

Kumbhakar, S. C., Wang, H.-J., \& Horncastle, A. P. (2015). A practitioner's guide to stochastic frontier analysis using Stata. Cambridge: Cambridge University Press.

Läpple, D., \& Hennessy, T. (2015). Exploring the role of incentives in agricultural extension programs. Applied Economic Perspectives and Policy, 37(3), 403-417. http://dx.doi. org/10.1093/aepp/ppu037

Meeusen, W., \& Van Den Broeck, J. (1977). Efficiency estimation from Cobb-Douglas production functions with composed error. International Economic Review, 18(2)

Mendes, Á. N. (2005). Financiamento, gasto e gestão do Sistema Único de Saúde (SUS): a gestão descentralizada semiplena e plena do sistema municipal no estado de São Paulo (19952001)(Tese de doutorado). Universidade Estadual de Campinas, Campinas.

Miziara, F. (2007). Extensão rural no estado de Goiás: produção familiar e modernidade reflexiva. Estudos, 34(9/10), 659-675.

Oliveira, G. R., Araújo, F. M., \& Queiroz, C. C. (2017). A importância da assistência técnica e extensão rural (ATER) e do crédito rural para a agricultura familiar em Goiás. Boletim Goiano de Geografia, 37(3), 529-551.

Pastor, J. T. (1996). Chapter 3: Translation invariance in data envelopment analysis: a generalization. Annals of Operations Research, 66, 91-102

Peixoto, M. (2014). Mudanças e desafios da extensão rural no Brasil. In A. M. Buainain, E. Alves, J. M. Silveira \& Z. Navarro (Eds.), O mundo rural no Brasil do século 21: A formação de um novo padrão agrário e agrícola (pp. 891-924). Brasília: Embrapa.

Peixoto, M. (2020). Assistência Técnica e Extensão Rural: Grandes deficiências ainda persistem. In J. E. R. Vieira Filho \& J. G. Gasques (Orgs.), Uma jornada pelos contrastes do Brasil: cem anos do Censo Agropecuário (pp. 323-338). Brasília: IPEA.

Pettan, K. B. (2010). A Política Nacional de Assistência Técnica e Extensão Rural (PNATER): percepções e tendências(Tese de doutorado). Universidade Estadual de Campinas, Campinas. 
Ray, S. C. (1991). Resource-use efficiency in public schools: a study of Connecticut data. Management Science, 37(12), 1620-1628. http://dx.doi.org/10.1287/mnsc.37.12.1620

Reinhard, S., Lovell, C. A. K., \& Thijssen, G. (2002). Analysis of environmental efficiency variation. American Journal of Agricultural Economics, 84(4), 1054-1065.

Reis, P. R. C., Silveira, S. F. R., \& Braga, M. J. (2013). Previdência social e desenvolvimento socioeconômico: impactos nos municípios de pequeno porte de Minas Gerais. Revista de Administração Pública, 47(3), 623-646. http://dx.doi.org/10.1590/S0034-76122013000300005

Rocha Junior, A. B., Freitas, J. A., Cassuce, F. C. C., \& Costa, S. M. A. L. (2019). Análise dos determinantes da utilização de assistência técnica por agricultores familiares do Brasil em 2014. Revista de Economia e Sociologia Rural, 57(2), 181-197. http://dx.doi.org/10.1590/18069479.2019.184459

Rocha Junior, A. B., Silva, R. O., Peterle Neto, W., \& Rodrigues, C. T. (2020). Efeito da utilização de assistência técnica sobre a renda de produtores familiares do Brasil no ano de 2014. Revista de Economia e Sociologia Rural, 58(2), 1-16. http://dx.doi.org/10.1590/1806-9479.2020.194371

Silva, F. P., Araujo, J. A., Costa, E. M., \& Vieira Filho, J. E. R. (2019). Eficiência técnica e heterogeneidade tecnológica na agropecuária das regiões semiárida e não semiárida do Nordeste brasileiro. Revista de Economia e Sociologia Rural, 57(3), 379-395.

Silva, J. L. M., \& Almeida, J. C. L. (2012). Eficiência no gasto público com educação: uma análise dos municípios do Rio Grande do Norte. Planejamento e Políticas Públicas, (39), 221-244.

Simper, R., Hall, M. J. B., Liu, W., Zelenyuk, V., \& Zhou, Z. (2017). How relevant is the choice of risk management control variable to non-parametric bank profit efficiency analysis? The case of South Korean banks. Annals of Operations Research, 250(1), 105-127. http://dx.doi. org/10.1007/s10479-015-1946-x

Sousa, M. da C. S., \& Ramos, F. S. (1999). Eficiência técnica e retornos de escala na produção de serviços públicos municipais: o caso do nordeste e do sudeste brasileiro. Revista Brasileira de Economia, 53(4), 433-461.

Takahashi, K., Mano, Y., \& Otsuka, K. (2019). Learning from experts and peer farmers about rice production: experimental evidence from Cote d'Ivoire. World Development, 122, 157-169. http://dx.doi.org/10.1016/J.WORLDDEV.2019.05.004

Tung, S. J., Gan, G. Y., Chyr, W. L., \& Lee, H. S. (2018). Efficiency measures for VRM models dealing with negative data in DEA. Journal of Marine Science and Technology, 26(2), 180-184. http:// dx.doi.org/10.6119/JMST.2018.04_(2).0005

Vicente, I., Borges, S., \& Wander, A. E. (2018). O financiamento do agronegócio em Goiás. Revista de Política Agrícola, 27(2), 130.

Vieira Filho, J. E. R. (2019). Sustentabilidade produtiva do agronegócio brasileiro. In IPEA (Org.), Diagnóstico e desafios da agricultura brasileira. Rio de Janeiro: IPEA. 